\title{
黄土丘陵区刺槐和侧柏人工林树干液流特征及其 对降水的响应
}

\author{
吴 旭 ${ }^{1}$ 陈云明 $2,3^{*}$ 唐亚坤 ${ }^{2,3}$
}

${ }^{1}$ 西北农林科技大学水土保持研究所, 陕西杨凌 712100 ; $^{2}$ 西北农林科技大学水土保持研究所黄土高原土壤侵蚀与早地农业国家重点实验室, 陕西杨凌 $712100{ }^{3}$ 中国科学院水利部水土保持研究所, 陕西杨凌 712100

摘 要 水分供应不足及水热不同步常导致黄土丘陵地区在春末和夏初出现季节性干旱。为阐明该地区主要造林树种的蒸腾 耗水特征及其对降水的响应, 使用热扩散式树干茎流计(TDP)于2009年4-10月对黄土丘陵区安塞国家生态试验站刺槐 (Robinia pseudoacacia) 和侧柏(Platycladus orientalis) 的树干液流密度 $\left(F_{\mathrm{d}}\right)$ 进行连续观测, 并同步测定了气象、土壤水分等环境 因子。结果表明: 刺槐和侧柏在生长季内不同生长时期的 $F_{\mathrm{d}}$ 均表现为单峰型日变化特征, 刺槐最高液流峰值为 0.12068 $\mathrm{m}^{3} \cdot \mathrm{m}^{-2} \cdot \mathrm{h}^{-1}$, 是侧柏最高液流值 $\left(0.03737 \mathrm{~m}^{3} \cdot \mathrm{m}^{-2} \cdot \mathrm{h}^{-1}\right)$ 的3.23倍。除生长旺盛季(7-8月)外, 刺槐和侧柏降水后的 $F_{\mathrm{d}}$ 明显高于降水 前。同时反映水汽压差 $(V P D)$ 和太阳辐射 $\left(R_{\mathrm{s}}\right)$ 的蒸腾变量 $(V T)$ 能够很好地模拟 $F_{\mathrm{d}}$, 且两者呈显著的指数正相关关系, 随 $V T$ 的增 加 $F_{\mathrm{d}}$ 逐渐增大, $V T$ 增加到 $50 \mathrm{kPa}\left(\mathrm{W} \cdot \mathrm{m}^{-2}\right)^{1 / 2}$ 左右时, $F_{\mathrm{d}}$ 的变化趋于稳定; 通过对降水前后两个树种水力导度(拟合参数 $b$ 值)分析, 相对于侧柏, 刺槐更易受降水的影响 $(p<0.001)$ 。因此, 可认为刺槐是降水敏感型植物, 而侧柏是降水不敏感型植物。该研究 通过分析黄土丘陵区人工林树种对降水的差异性响应, 从树木水分利用方面能够为当地生态恢复过程中人工林的管理提供 科学依据。

关键词 刺槐, 侧柏, 树干液流, 环境因素, 水分利用

引用格式: 吴旭, 陈云明, 唐亚坤 (2015). 黄土丘陵区刺槐和侧柏人工林树干液流特征及其对降水的响应. 植物生态学报, 39, 1176-1187. doi: $10.17521 /$ cjpe.2015.0114

\section{Sap flow characteristics and its responses to precipitation in Robinia pseudoacacia and Platy- cladus orientalis plantations}

\author{
WU Xu' ${ }^{1}$, CHEN Yun-Ming ${ }^{2,3^{*}}$, and TANG Ya-Kun ${ }^{2,3}$ \\ ${ }^{1}$ Institute of Soil and Water Conservation, Northwest A\&F University, Yangling, Shaanxi 712100, China; ${ }^{2}$ State Key Laboratory of Soil Erosion and Dry-land \\ Farming on Loess Plateau, Institute of Soil and Water Conservation, Northwest A\&F University, Yangling, Shaanxi 712100, China; and ${ }^{3}$ Institute of Soil and \\ Water Conservation, Chinese Academy of Sciences and Ministry of Water Resources, Yangling, Shaanxi 712100, China
}

\section{Abstract}

Aim In the loess hilly region, drought stress frequently occurs during the late spring and early summer as a result of insufficient water supply and asynchronous changes between temperature and precipitation. Our objective was to quantify the characteristics of water-consumption through transpirations and their responses to precipitation in the dominant plantations in this region.

Methods Thermal dissipation probe (TDP) was used to measure the sap flow density $\left(F_{\mathrm{d}}\right)$ of Robinia pseudoacacia and Platycladus orientalis from April through October in 2009 in Ansai National Ecological Experimental Station. Environmental variables, including meteorological factors and soil water content, were simultaneously measured.

Important findings The diurnal variation of $F_{\mathrm{d}}$ exhibited a single-peak curve during the growing season of $R$. pseudoacacia and $P$. orientalis. The maximum $F_{\mathrm{d}}$ was three times greater in $R$. pseudoacacia $(0.12068$ $\mathrm{m}^{3} \cdot \mathrm{m}^{-2} \cdot \mathrm{h}^{-1}$ ) than that in P. orientalis $\left(0.03737 \mathrm{~m}^{3} \cdot \mathrm{m}^{-2} \cdot \mathrm{h}^{-1}\right)$. Except in the rapid-growth season (July to August), the $F_{\mathrm{d}}$ of these two species during the post-precipitation period were significantly higher than that during the pre-precipitation period. The $F_{\mathrm{d}}$ of $P$. orientalis and $R$. pseudoacacia was well fitted with transpiration (VT), an integrated index calculated from both vapor pressure deficit $(V P D)$ and solar radiation $\left(R_{\mathrm{s}}\right)$, using an exponential saturation function. Generally, $F_{\mathrm{d}}$ increased in response to rising $V T$, while these values tended to be stable when

收稿日期Received: 2015-05-08 接受日期Accepted: 2015-10-24

* 通讯作者Author for correspondence (E-mail: ymchen@ms.iswc.ac.cn) 
$V T$ reached about $50 \mathrm{kPa}\left(\mathrm{W} \cdot \mathrm{m}^{-2}\right)^{1 / 2}$. Furthermore, $R$. pseudoacacia showed more sensitive to precipitation $(p<$ 0.001 ) than $P$. orientalis, according to different hydraulic conductance model coefficients (fitting parameter $b$ ) between pre- and post-precipitation periods. Therefore, $R$. pseudoacacia could be considered as a precipitation-sensitive species, while $P$. orientalisasa precipitation-insensitive species. Through analyzing the different responses of plantation species to precipitation in the loess hilly region, this study provides a scientific basis for the local plantation management from the aspect of tree water use during ecological restoration.

Key words Robinia pseudoacacia, Platycladus orientalis, sap flow, environmental parameters, water use

Citation: Wu X, Chen YM, Tang YK (2015). Sap flow characteristics and its responses to precipitation in Robinia pseudoacacia and Platycladus orientalis plantations. Chinese Journal of Plant Ecology, 39, 1176-1187. doi: 10.17521/cjpe.2015.0114

黄土丘陵区具有典型的大陆性季风气候特征, 植被地带属于暖温带落叶阔叶林向干旱草原过渡的 森林草原区(吴钦孝和杨文治, 1998)。因长期不合理 的土地利用, 该地区天然植被已遭到严重破坏, 水 土流失严重, 人工造林已成为该地区水土流失治理 和生态环境改善的主要途径(高世铭等, 2003)。该地 区年降水量 $500 \mathrm{~mm}$, 且年际和年内降水分布不均 匀, 形成 “冬干、春早、夏多、秋少”的季节水分分 配特征(山仑, 1988)。目前, 人工林占该地区森林面 积的59.8\% (何永涛等, 2004; 陈云明等, 2005), 由 于在造林过程中没有充分考虑该地区水资源的特 点, 片面追求经济效益, 引进生产力高而耗水量大 的树种, 导致植被建设中人工林成活率低、保存率 低、生长率低的“三低”问题和“小老头树”现象普遍 存在(侯庆春等, 1999; 张金屯, 2004)。因此, 需要对 当地人工林树木的蒸腾耗水特征及其对环境因素 (特别是季节性干旱或降水)的响应进行研究, 从而 为该地区生态恢复过程中人工林水分利用的稳定性 评估及可持续性管理提供科学依据。

刺槐(Robinia pseudoacacia)根系发达、生长迅 速、耐干旱㾉薄, 是黄土丘陵区的主要造林树种(森 敏等, 2008)。侧柏(Platycladus orientalis)作为乡土树 种, 与刺槐一样具有耐干旱、㾑薄的特点, 对保持水 土、改善生态环境也起到了重要的作用(魏天兴等, 1991)。有研究表明: 黄土高原地区刺槐在造林5-8 年后, 部分纯林生长不良, 呈衰退趋势, 林下“土壤 干层”现象严重, 难以自然更新(侯庆春和韩荵莲, 2000), 在黄土丘陵区幼龄侧柏成活率高, 常被用来 更新退化的人工刺槐林(许鹏辉等, 2009)。目前关于 刺槐和侧柏耗水研究主要侧重这两个树种的蒸腾耗 水特征及其控制因素(马履一和王华田, 2002; 于占 辉等, 2009a), 而对生长季内不同生长时期的蒸腾 耗水特征及其对季节性干旱或降水的生理响应还需
进一步分析, 以期从水分利用方面阐明黄土丘陵区 刺槐和侧柏人工林的区域环境适应机制。

树干液流是衡量植物蒸腾耗水的一个重要生理 指标, 能够反映植物生理特性和环境因素对植物水 分利用的综合调节作用(汪㳥和王健, 2012)。多数研 究表明干旱时期树干液流密度 $\left(F_{\mathrm{d}}\right)$ 明显降低, 而降 水能够缓解干旱对液流的影响, 但降水的这种缓解 作用因植物自身的生理调节不同存在差异(徐贵青 和李彦, 2009)。Burgess (2006)对受夏季降水影响的 澳大利亚西南部11种植物的研究发现: $34 \mathrm{~mm}$ 的降 水后, Isopogon gardneri灌从蒸腾迅速增加5倍, 小 的降水(4 mm或 $2 \mathrm{~mm}$ )对其没有影响; 其他灌从(例 如Allocausarina campestris) 由于夏季休眠的影响, 随降水的发生 $(34 \mathrm{~mm})$, 其蒸腾只增加了2倍, 较小 降水 $(4 \mathrm{~mm}$ 或 $2 \mathrm{~mm})$ 后液流有微弱的增加; 需要注 意的是深根系Eucalyptus wandoo 的液流更依赖于前 期的土壤含水量, 而非夏季降水。然而, 由于生长季 内不同生长时期影响液流的主导环境因素也存在较 大差异, 因此, 分析生长季内不同生长时期植物对 季节性干旱或降水响应的敏感性差异, 能够更好地 揭示植物水分利用状况及其对水分环境条件变化的 适应性(Hölscher et al., 2005)。有研究表明 $F_{\mathrm{d}}$ 受太阳 辐射 $\left(R_{\mathrm{S}}\right)$ 和水汽压差 $(V P D)$ 的影响, 选取能同时表征 $R_{\mathrm{s}}$ 和 $V P D$ 协同变化的蒸腾变量 $(V T)$ 可以综合地反映 液流对环境因素的响应特征(Campbell \& Norman, 1998; Iida et al., 2006)。Pataki等(2000)在对Populus tremuloides 和Pinus thunbergii耐干旱程度的研究中 发现: 当土壤水分从 $0.35 \mathrm{~m}^{3} \cdot \mathrm{m}^{-3}$ 下降到 $0.24 \mathrm{~m}^{3} \cdot \mathrm{m}^{-3}$ 时, 两个树种 $F_{\mathrm{d}}$ 的最大值都降低 (生长季末期), Pinus thunbergii 的 $F_{\mathrm{d}}$ 变化对 $V P D$ 敏感, 而Populus tremuloides 对土壤水分亏缺不敏感, 在生长末期仍 保持较高的 $F_{\mathrm{d}}$ 。因此, 通过分析不同植物 $F_{\mathrm{d}}$ 对 $V T$ 的 差异性响应以及降水的影响, 能够深入了解气候变 
化条件下植物的适应性, 并为植被恢复与重建提供 依据。

本研究以黄土丘陵区刺槐和侧柏人工林为研究 对象, 采用热扩散探针技术进行树干液流的连续观 测。主要目标: (1)结合降水事件, 分析生长季内不同 生长时期(生长季初期(4-6月)、生长旺盛季(7-8月)、 生长季末期(9-10月))降水前后刺槐和侧柏树干液流 变化特征, 明确降水对刺槐和侧柏树干液流的影 响; (2)探讨不同生长时期刺槐和侧柏树干液流对 $V T$ 的生理响应以及降水的影响; (3)结合刺槐和侧柏树 干液流的变化特征及其生理响应，判断两个树种对 降水响应的敏感性。

\section{1 材料和方法}

\section{1 研究区概况}

研究区位于陕西安塞县中国科学院安塞水土保 持综合试验站的山地试验场 $\left(109.32^{\circ} \mathrm{E}, 36.85^{\circ} \mathrm{N}\right.$, 海拔1 $198 \mathrm{~m})$, 属典型的黄土丘陵沟壑区。水土流失 面积占该地区总面积的 $96 \%$, 属典型的生态环境脆 弱区。该地区主要受暖温带半干旱大陆性季风气候 的影响, 年平均气温 $8.8{ }^{\circ} \mathrm{C}$, 极端最高和最低温度 分别为 $36.8{ }^{\circ} \mathrm{C}$ 和 $-23.6{ }^{\circ} \mathrm{C}$, 年降水量 $500 \mathrm{~mm}$, 其中 6-9月雨季降水占全年降水量的72.9\%。土壤以黄绵 土为主，约占该地区总面积的 $95 \%$, 土壤容重约为 $1.32 \mathrm{~g} \cdot \mathrm{cm}^{-3}$, 土壤孔隙度为 $57.77 \%$; 主要植物有刺 槐、侧柏、沙棘(Hippophae rhamnoides)、沙地锦鸡 儿(Caragana davazamcii)、白羊草 (Bothriochloa ischaemum)、细裂叶莲蒿(Artemisia gmelinii)等。

刺槐人工林固定监测样地: 坡向东偏北 $20^{\circ}$ 、坡 度 $25^{\circ}$, 于1968年造林, 1994年左右进行了间伐, 现 林分保存密度为 850 株 $\cdot \mathrm{hm}^{-2}$ 、平均胸径 $20.6 \mathrm{~cm}$ 、平 均树高 $13.5 \mathrm{~m}$ 。林下植被盖度为 $30 \%$, 以长芒草 (Stipa bungeana) 为主。
侧柏人工林固定监测样地: 地形地貌与刺槐林 地相同，于1982年栽植，林分密度为 2230 株 $\cdot \mathrm{hm}^{-2}$ 、 平均地径 $8.8 \mathrm{~cm}$, 平均树高 $5 \mathrm{~m}$ 。林木地径主要为 8-10 cm, 占整个林分的 $86 \%$; 林下植被极少, 地表 枯落物较多。

\section{2 研究方法}

\subsection{1 树干液流测定}

在刺槐和侧柏林内分别设置 $20 \mathrm{~m} \times 20 \mathrm{~m}$ 的样 地，选择不同径阶、生长良好、树体通直、无被挤 压的刺槐和侧柏样木各 4 株(表1), 应用热扩散茎流 计(TDP-10, Dynamax, Houston, USA)于2009年4月 20日-10月31日进行树干液流的连续观测。为避免太 阳直射引起的测量误差, 将探针安装在树干北面。 仪器的具体安装如下: (1)用小刀在样木离地面30 $\mathrm{cm}$ (侧柏)或 $130 \mathrm{~cm}$ (刺槐)处将树干粗死皮刮去; (2) 用直径为 $2 \mathrm{~mm}$ 的钻头在探针安装位置上下钻出 2 个 $10 \mathrm{~mm}$ 深的小孔, 两孔间距为 $15 \mathrm{~cm}$, 将 $10 \mathrm{~mm}$ 长的 热源探针和感应探针分别逐渐插入上部孔和下部 孔; (3)用玻璃胶将探针与树体之间的空隙涂抹封好, 以防止树干流下的水分与探针接触; (4)用胶带纸将 探针尾部所连的电缆线小心固定在树干上, 并与电 源(12 V电源适配器)连接; (5)用锡箔护罩将安装探 头所在的树干部分包裹起来; (6)使用CRl000数据采 集器(Campbell Scientific, Logen, USA)设置采样程 序记录并存储数据, 数据采样间隔为 $30 \mathrm{~s}$, 输出的 数据为每小时的平均值 (于占辉等, 2009b; 吴芳等, 2010)。根据通用的Granier液流计算公式(Granier, 1987)计算 $F_{\mathrm{d}}$ :

$$
F_{\mathrm{d}}=0.000119 \times\left[\left(\Delta T_{\max }-\Delta T\right) / \Delta T\right]^{1.231} \times 3600(1)
$$
式中, $F_{\mathrm{d}}$ 是树干液流密度 $\left(\mathrm{m}^{3} \cdot \mathrm{m}^{-2} \cdot \mathrm{h}^{-1}\right) ; \Delta T_{\max }$ 是上下 探针之间的昼夜最大温差值; $\Delta T$ 是瞬时温差值。

\subsection{2 气象因素测定}

距固定样地 $200 \mathrm{~m}$ 处有中国科学院安塞试验站

表1 被测样木基本参数

Table 1 Stand structural characteristics of two plantations

\begin{tabular}{|c|c|c|c|c|c|}
\hline $\begin{array}{l}\text { 树种 } \\
\text { Species }\end{array}$ & $\begin{array}{c}\text { 样木序号 } \\
\text { Sample tree No. }\end{array}$ & $\begin{array}{c}\text { 林龄 } \\
\text { Stand age (a) }\end{array}$ & $\begin{array}{c}\text { 树高 } \\
\text { Tree height (m) }\end{array}$ & $\begin{array}{c}\text { 胸径/地径 } \\
D B H / D G H(\mathrm{~cm})\end{array}$ & $\begin{array}{c}\text { 边材厚度 } \\
\text { Sapwood width }(\mathrm{cm})\end{array}$ \\
\hline \multirow{4}{*}{ 刺槐 Robinia pseudoacacia } & 1 & 41 & 13.5 & 20.5 & 1.2 \\
\hline & 2 & 41 & 13.0 & 17.3 & 1.0 \\
\hline & 3 & 41 & 13.0 & 18.0 & 1.1 \\
\hline & 4 & 41 & 14.0 & 24.0 & 1.3 \\
\hline \multirow[t]{4}{*}{ 侧柏 Platycladus orientalis } & 1 & 27 & 5.2 & 8.7 & 2.9 \\
\hline & 2 & 27 & 5.3 & 9.6 & 3.2 \\
\hline & 3 & 27 & 4.0 & 9.5 & 3.1 \\
\hline & 4 & 27 & 4.6 & 10.2 & 3.3 \\
\hline
\end{tabular}

$\overline{D B H}$, diameter at breast height; $D G H$, diameter at ground height. 
自动气象观测站, 测定的指标主要有太阳辐射(LI190SZ, Li-COR, Lincoln, USA)、大气温度(HMP45D, Vaisala, Helsinki, Finland)、相对湿度 (HMP45D, Vaisala, Helsinki, Finland)、风速(VAA151, Vaisala, Helsinki, Finland)、降水(DRD11A Rain Detector, Vaisala, Helsinki, Finland)等指标, 1 h记录1次。 水汽压差 $(V P D)$ 使用以下公式(许文滔等, 2007) 计算:

$$
\begin{aligned}
& e_{\mathrm{s}}(T)=0.611 \times \exp (17.502 /(T+240.97)) \\
& V P D=e_{\mathrm{s}}(T)-e_{\mathrm{a}}=e_{\mathrm{s}}(T)\left(1-h_{\mathrm{r}}\right)
\end{aligned}
$$

式中, $e_{\mathrm{s}}(T)$ 为 $T$ 大气温度下的饱和水汽压差 $(\mathrm{kPa}) ; T$ 为大气温度 $\left({ }^{\circ} \mathrm{C}\right) ; e_{\mathrm{a}}$ 为周围气体水汽压 $(\mathrm{kPa}) ; h_{\mathrm{r}}$ 为相 对湿度 $(\%) ; V P D$ 为水汽压差 $(\mathrm{kPa})$ 。

\subsection{3 土壤水分测定}

在刺槐和侧柏林内矩形样地对角线分别随机布 置3个土壤水分监测点。利用中子仪(CNC503B，北 京渠道科学器材有限公司)分别在每月 $1 、 5 、 10 、 15 、$ 20、25日测定土壤水分。测量深度为 $200 \mathrm{~cm}$, 按层 次测量, 每 $10 \mathrm{~cm}$ 记录读数一次, 用 3 个测点数据的 平均值来表示此时期的土壤平均含水量。考虑实地 测定时因质地等原因造成的测量误差, 本文采用烘 干法测定土壤的容重和含水量, 并以所得的数据做 出热中子数与体积含水量的标定曲线, 于每月 15 日 对中子仪所测量的数据进行校正, 即采用中子土壤 水分仪的标定曲线标定(刘玉华等, 2007):

$$
Y=A x+B
$$

式中, $Y$ 为土壤体积含水量; $x$ 为计数率比(中子仪实 测计数率与其标准计数率之比, 其大小反映仪器的 灵敏度); $A 、 B$ 为标定曲线的斜率和截距, 受土壤容 重、质地、化学组成的影响。

\section{3 数据分析}

为研究整个生长季内刺槐和侧柏树干液流对降 水的响应, 在生长季初期(4-6月)、生长旺盛季(7-8 月)和生长季末期(9-10月)各选择1次降水事件为中 心时间点, 通过对比降水前后(分别 4 天) 所选样木树 干液流的变化特征, 分析刺槐和侧柏的水分利用变 化状况。本研究选取能同时反映太阳辐射 $\left(R_{\mathrm{S}}\right)$ 和 $V P D$ 协同变化的 $V T$, 分析较短时间尺度下两个树种对环 境因子的响应, 使用下列公式(Iida et al., 2006)计算:

$$
V T=V P D \times R_{\mathrm{s}}^{1 / 2}
$$

已有研究表明, 可以使用下列指数饱和函数来 分析 $F_{\mathrm{d}}$ 和 $V T$ 的关系(Oren et al., 1996; Ewers et al.,
2007; Du et al., 2011):

$$
Y=a(1-\exp (-b x))
$$

式中, $x$ 为 $V T, Y$ 为 $F_{\mathrm{d}} ; a$ 和 $b$ 为曲线拟合参数, $a$ 代表曲 线偏移横坐标的程度, $a$ 值越大表明所选样木树干液 流受环境因素的影响越大; $b$ 代表拟合曲线的斜率 (水力导度), 指示了树木导水系统的水分供应能力, $b$ 值越大, 表明树木导水能力越强, 通过不同植物水 力导度的分析可以了解植物对水分环境条件的差异 性响应。

本研究使用Excel软件对树干液流数据进行整 理和计算, 使用Origin 8.0进行方程拟合, 使用SPSS 16.0 (SPSS, USA) 对刺槐和侧柏生长季内不同生长 时期树干液流对降水的差异性响应进行分析, 使用 一般线性模型(GLM)对降水前后 $F_{\mathrm{d}}$ 和 $V T$ 的拟合曲线 参数进行显著性检验(Chow, 1960; Wei et al., 2013)。

\section{2 结果}

\section{1 生长季内环境因素的变化特征}

观测时期(4月20-10月31日)研究区的总降水量 为492 mm, 降水分布不均匀(图1), 其中约 70\%的降 水集中在7-9月, 春末和夏初则明显不足。整个生长 季刺槐和侧柏样地土壤含水量的变化特征为: 干旱 季节(4-6月)土壤含水量较低, 7月份开始逐步回升, 9月份土壤含水量达到整个生长季的最高水平, 10 月 份又开始降低, 变化范围6.8\%-10.6\%。

降水前和降水后刺槐和侧柏样地0-200 cm土层 土壤水分随土层深度的增加呈现基本相同的变化规 律: 两个样地0-120 cm 土层土壤体积含水量的变化 幅度大于 $120 \mathrm{~cm}$ 以下土层的土壤体积含水量变化幅 度(图2)。降水主要对表层土壤水分产生影响, 生长 季初期(4-6月)降水后土壤体积含水量较降水前有 明显增加, 而生长旺盛季(7-8月), 由于所选时段降 水量较小, 降水对土壤水分影响也较小, 降水后较 降水前土壤含水量有降低趋势, 生长季末期(9-10 月)降水前后基本无变化。

土壤供水决定了树干液流的总体水平, 而气象 因素决定了树干液流的瞬间变动。图3为4-10月所选 研究时段 $R_{\mathrm{s}}$ 和日均 $V P D$ 变化特征。在这 3 个时间段 中, $R_{\mathrm{S}}$ 最高值 $\left(28003.2 \mathrm{~W} \cdot \mathrm{m}^{-2}\right)$ 和最低值(2 139.8 $\left.\mathrm{W} \cdot \mathrm{m}^{-2}\right)$ 均出现在 4-6月。雨季(7-9月)的辐射量明显 低于生长季初期(4-6月)。日均 $V P D$ 和 $R_{\mathrm{s}}$ 有相似的变 化趋势, 日均 $V P D$ 最高值 $(1.68 \mathrm{kPa})$ 和最低值 $(0.15$ 
$\mathrm{kPa}$ )也出现在生长季初期(4-6月)。

\section{2 刺槐和侧柏树干液流变化特征}

为了探讨降水前后刺槐和侧柏的树干液流变化 特征, 以生长季 3 个不同生长时期的降水事件为中
心，分别选取降水前后各4天的数据进行分析(图4)。 除生长旺盛季(7-8月), 刺槐和侧柏降水后 $F_{\mathrm{d}}$ 明显高 于降水前。刺槐和侧柏降水前后树干液流峰值都 为生长旺盛季最大, 其中刺槐液流峰值最大值

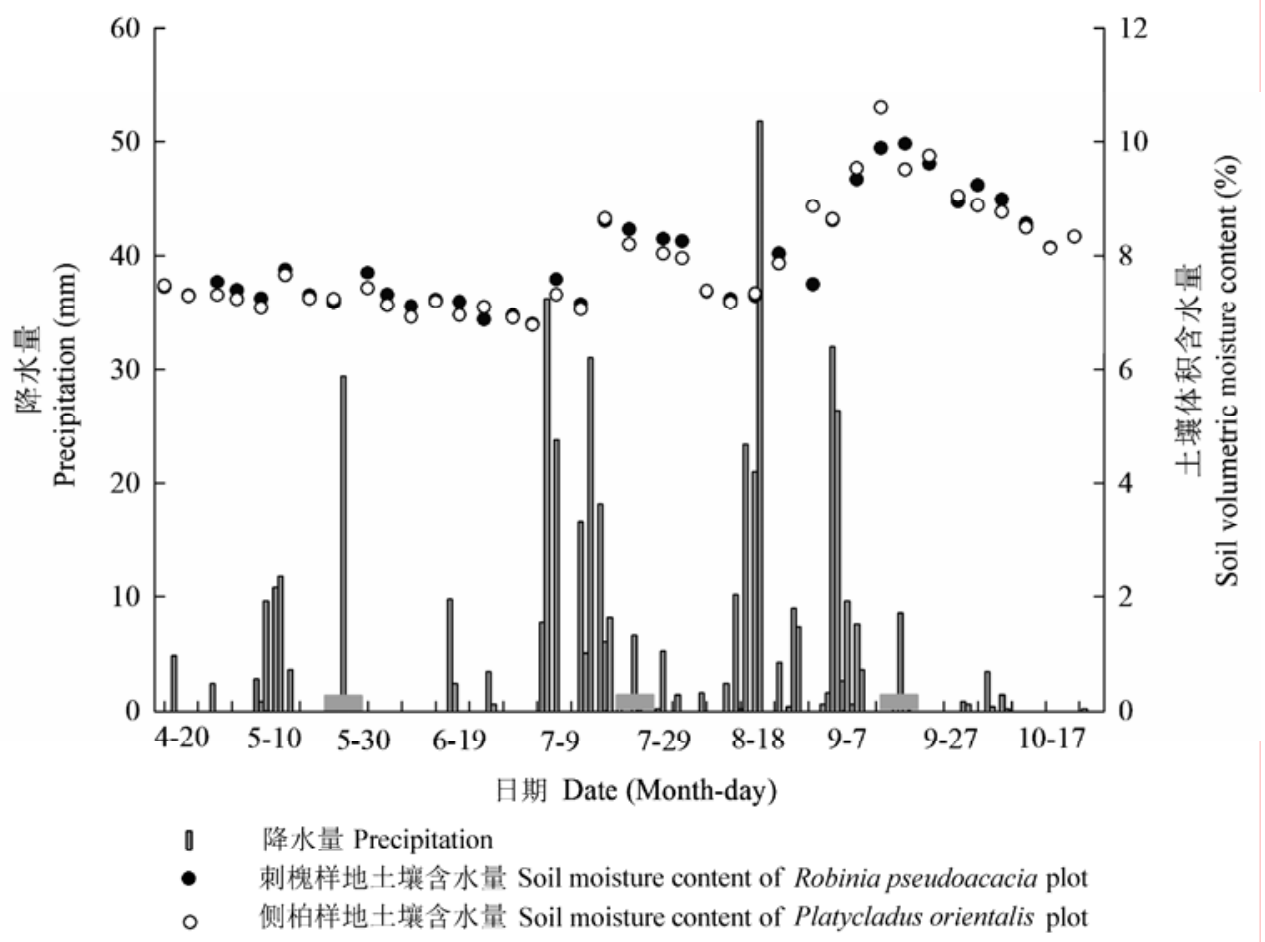

图1 整个生长季降水量和土壤体积含水量。横坐标上三个矩形方框标注时段为本研究分析的以3次降水事件为时间中心的生 长季内不同时期(3次降水事件分别为: 5月27-28日(30 mm)、7月26-27日 $(7 \mathrm{~mm})$ 和9月18-20日 $(9.2 \mathrm{~mm})$ )。土壤体积含水量数据 为 $0-200 \mathrm{~cm}$ 土层的平均值。

Fig. 1 Changes in precipitation and soil volumetric moisture content in the studied plots during the growing season. The marked time of three rectangular boxes on $\mathrm{X}$-axis are the study periods with the center of three precipitation events during the growing season on May 27 to $28(30 \mathrm{~mm})$, July 26 to $27(7 \mathrm{~mm})$ and September18 to $20(9.2 \mathrm{~mm})$. The soil volumetric moisture content data are averages in the depths of $0-200 \mathrm{~cm}$.

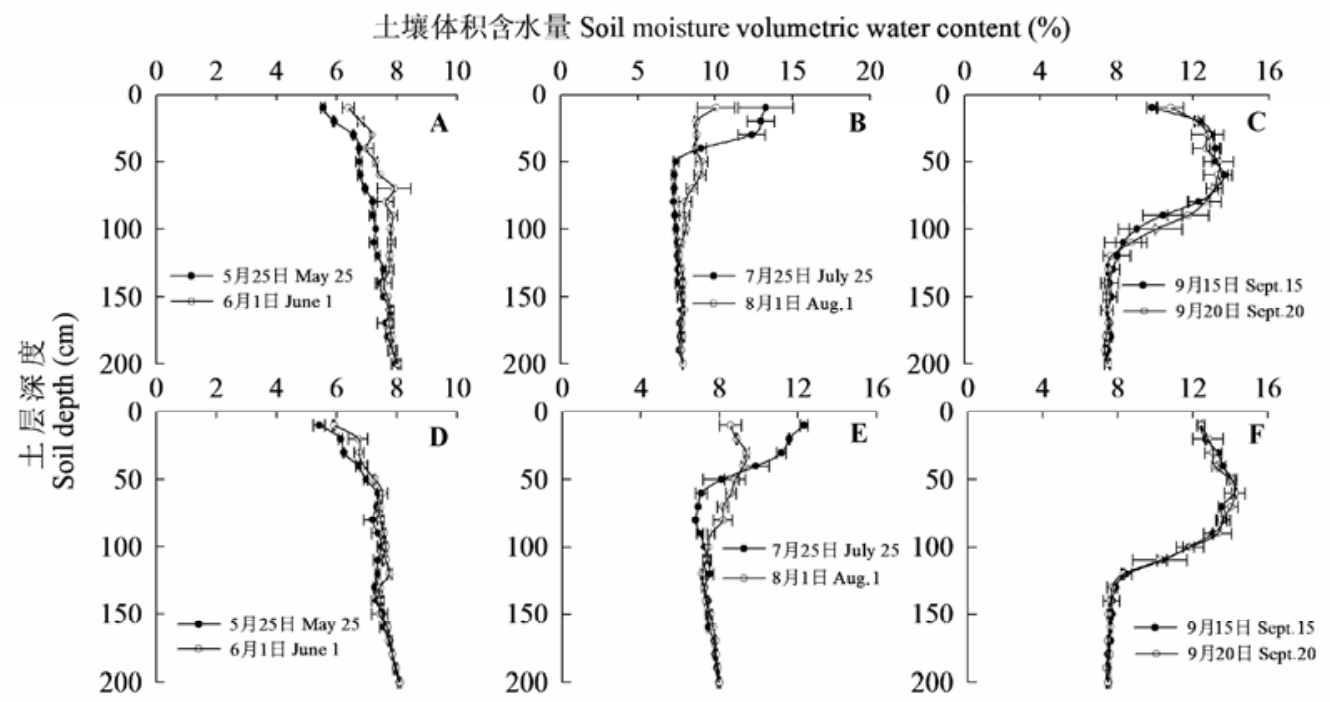

图2 生长季内不同生长时期刺槐(A-C)和侧柏(D-F)样地降水前后土壤体积含水量的变化(平均值土标准误差)。

Fig. 2 Soil volumetric moisture content in the Robinia pseudoacacia (A-C) and Platycladus orientalis (D-F) plantation in pre- and post-precipitation conditions, respectively (mean $\pm S E$ ). 


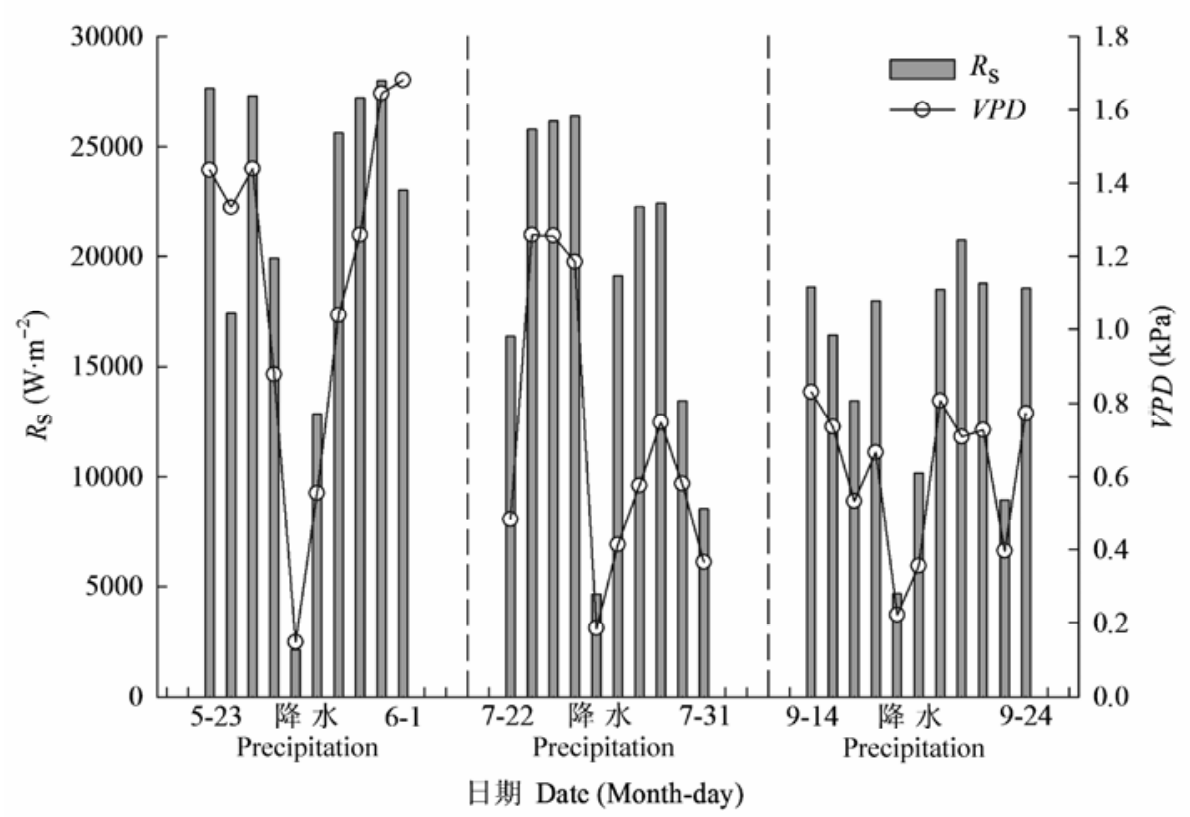

图3 所选时段刺槐和侧柏样地降水前后太阳辐射 $\left(R_{\mathrm{s}}\right)$ 和日均水汽压差 $(V P D)$ 的变化。本研究分析的以降水事件为中心的生长 季初期、生长旺盛季、生长季末期用虚线隔开。

Fig. 3 Daily sum of solar radiation $\left(R_{\mathrm{s}}\right)$ and daytime mean vapor pressure deficit $(V P D)$ in the two plantations measured on pre- and post-precipitation conditions during the selected periods, respectively. The study periods which with the center of three precipitation events in different growth periods were separated with dotted lines.

$\left(0.12068 \mathrm{~m}^{3} \cdot \mathrm{m}^{-2} \cdot \mathrm{h}^{-1}\right)$ 是侧柏最高液流峰值 $(0.03737$ $\mathrm{m}^{3} \cdot \mathrm{m}^{-2} \cdot \mathrm{h}^{-1}$ )的3.23倍(图4)。

从图4还可看出, 刺槐和侧柏在生长季内不同 生长时期降水前后树干液流都呈单峰型的日变化特 征: 7:00前后开始启动, 之后树干液流迅速增加, 在 10:00-13:00左右达到最大值，19:00前后开始下降， 直至次日树干液流启动之前降至最低值, 夜间仍有 微弱的液流存在, 且刺槐 $F_{\mathrm{d}}$ 高于侧柏。

刺槐和侧柏生长季内不同生长时期降水前后24 天的树干液流峰值时间频率分布也存在明显差异 (图5)。降水前刺槐的树干液流峰值时间频率分布较 宽, 约 1/3的峰值出现在13:00左右, 1/5的峰值出现 在15:00左右, 峰值时间的这种分布模式意味着刺 槐树干液流从启动一直活跃到午后(图5A)。而侧柏 降水前的树干液流峰值时间频率分布相对较窄, 约 4/5的峰值出现在11:00-13:00 (图5B)。降水后刺槐和 侧柏树干液流峰值时间频率分布都相对较窄, 大于 1/2的峰值都集中在12:00左右, 这可能与土壤水分 得到降水的补充有关。

刺槐和侧柏在不同观测时期降水前后树干液流 差异性分析见图6。整个生长季内降水前刺槐和侧柏 树干液流均为生长旺盛季(7-8月)最大, 与生长季初
期(4-6月)和末期(9-10月)差异性显著, 而生长季初 期和末期差异不显著, 降水后刺槐和侧柏不同生长 时期树干液流均无显著差异性。除7-8月的刺槐, 同 一生长时期刺槐和侧柏降水前后树干液流均有显著 性差异, 且降水后显著高于降水前(图6)。

\section{3 刺槐和侧柏树干液流对主要环境因素的响应 特征}

树木蒸腾耗水过程受到树木自身特性和环境因 素的共同影响。在较短的时间尺度(1 h), 其变化特 征主要受大气对水分的需求 $(V P D)$ 和能量的供给 $\left(R_{S}\right)$ 即 $V T$ 的影响。本研究选取了 $R_{S}>0$ 的液流数据, 分析生长季内不同生长时期刺槐和侧柏树干液流对 降水前后 $V T$ 的响应特征(图7)。

生长季内不同生长时期降水前后刺槐和侧柏的 $F_{\mathrm{d}}$ 和 $V T$ 之间更符合指数饱和拟合曲线方程(方程 (5))。随着 $V T$ 的增加 $F_{\mathrm{d}}$ 逐渐增大, $V T$ 增加到 $50 \mathrm{kPa}$ $\left(\mathrm{W} \cdot \mathrm{m}^{-2}\right)^{1 / 2}$ 左右时, $F_{\mathrm{d}}$ 的变化趋于稳定(图7)。生长季 内不同生长时期降水前后刺槐和侧柏 $F_{\mathrm{d}}$ 和 $V T$ 的曲 线拟合参数 $(a$ 或 $b$ )存在明显差异(表 2$)$ 。同一生长时 期拟合曲线降水后较降水前都不同程度地向上发生 偏移, 除生长旺盛季(7-8月), 降水后刺槐曲线向上 偏移量整体大于侧柏，表明刺槐对降水前后环境因 


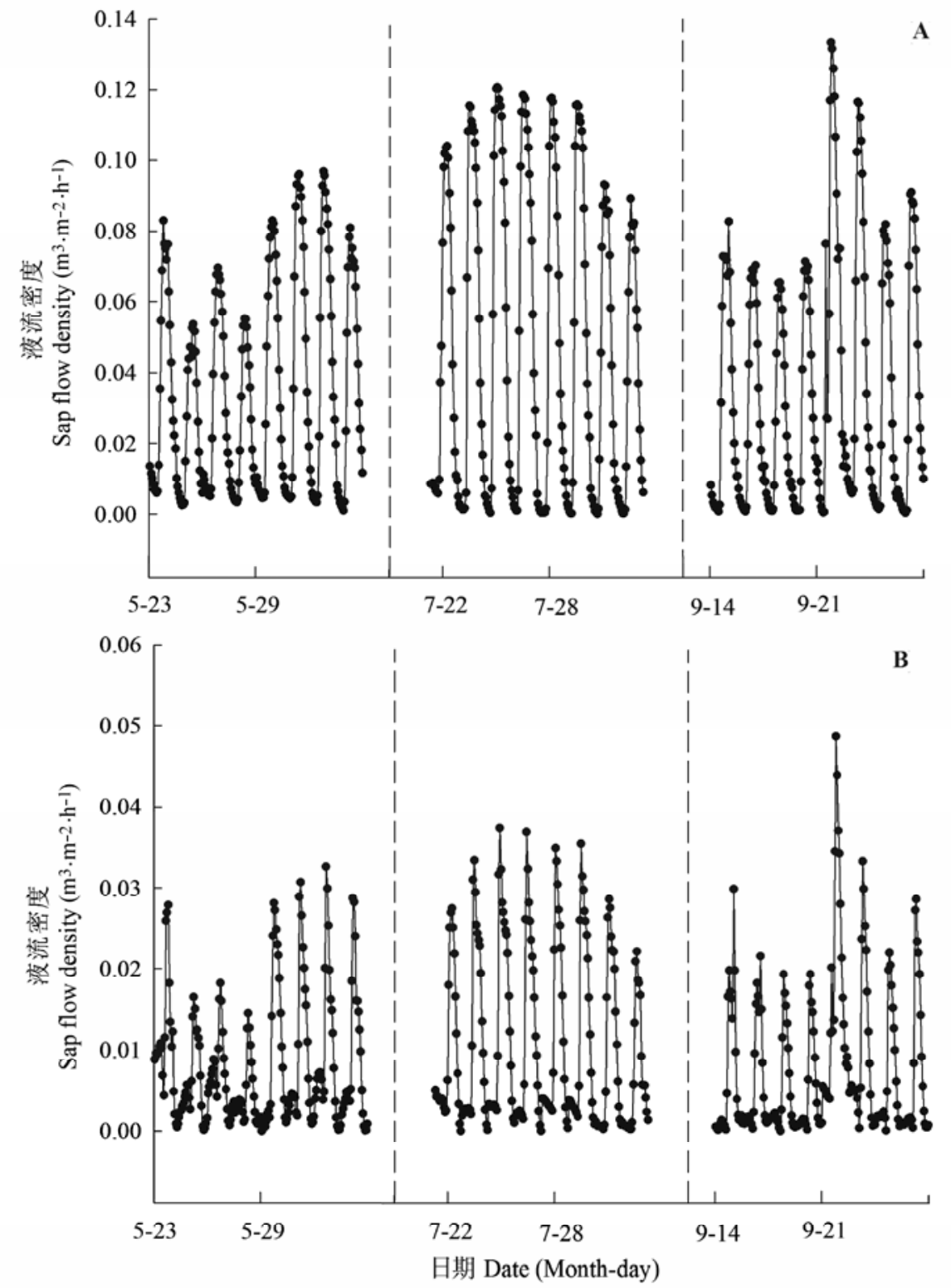

图4 生长季内不同生长时期降水前后刺槐(A)和侧柏(B)树干液流变化特征。图中生长季初期、生长旺盛季、生长季末期用虚 线隔开。

Fig. 4 Changes in sap flow density in Robinia pseudoacacia (A) and Platycladus orientalis (B) measured on pre- and post-precipitation conditions, respectively, during the different growth period. The different growth periods in growing season were separated with dotted lines.

素的变化响应敏感 $(p<0.001)$, 而降水前后环境条 件的变化对侧柏的蒸腾耗水影响相对较小。整个生 长季内刺槐拟合曲线斜率(即水力导度)基本呈增加 趋势, 侧柏呈现先增加后减小的变化趋势, 且同一 月份降水前后刺槐导水度比侧柏的变化显著 $(p<$ 0.001), 刺槐的导水能力高于侧柏。

\section{3 讨论}

刺槐和侧柏的液流密度 $\left(F_{\mathrm{d}}\right)$ 均表现为生长旺盛
季(7-8月)较高, 而生长季初期(4-6月)和生长季末 期(9-10月)较低的趋势。降水前后刺槐和侧柏树干 液流日变化曲线均为单峰型, 但由于不同树种导水 结构及对光强的差异性响应, 其峰型的宽窄不同 (图4)。降水前刺槐的峰值时间频率分布较宽, 主要 集中在13:00-15:00, 侧柏的峰值时间频率分布相对 较窄, 主要集中在11:00-13:00。降水后刺槐和侧柏 峰值时间频率分布都相对较窄, 主要集中在12:00 左右。降水前后刺槐和侧柏峰值时间频率分布的差 

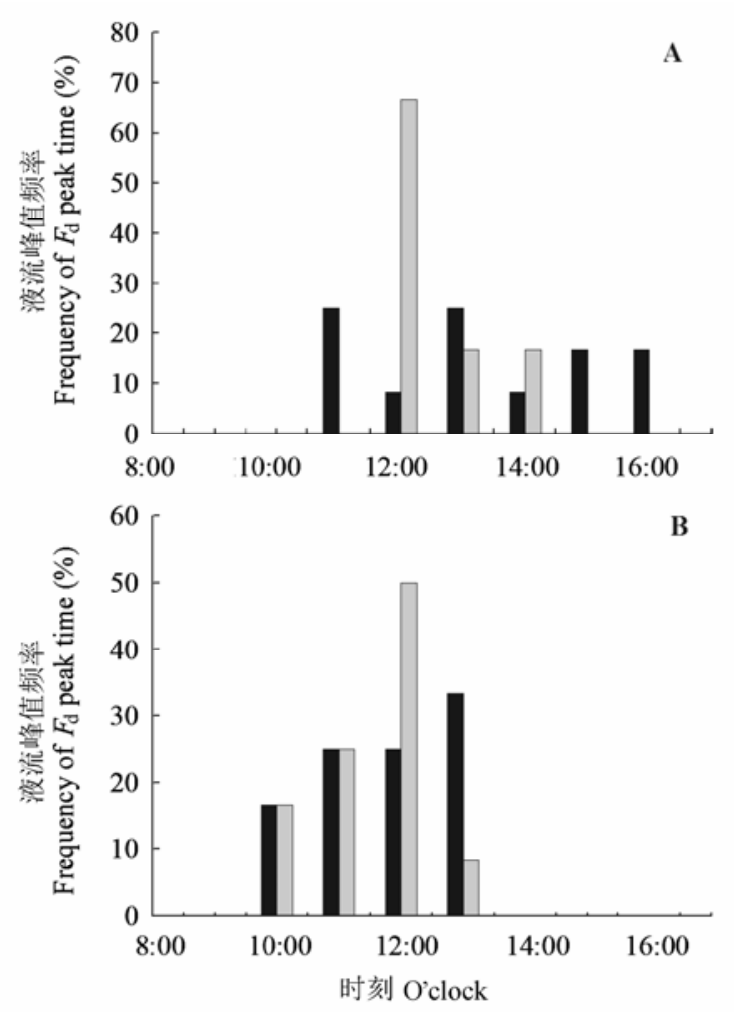

—降水前 Pre-precipitation $\square$ 降水后 Post-pricipitation

图5 生长季内不同生长时期降水前后刺槐(A)和侧柏(B) 液流峰值频率日变化。

Fig. 5 Frequency of sap flow density $\left(F_{\mathrm{d}}\right)$ peak time of Robinia pseudoacacia (A) and Platycladus orientalis (B) measured on pre- and post-precipitation conditions, respectively, during the different growth periods.

异除与降水使土壤水分状况得到暂时改善有关外 (图5), 可能还与林龄有关。同一树种不同林龄的峰 值时间频率分布存在差异，陕北沙地31-34年生小 叶杨(Populus simonii)液流达到峰值的时间较早, 主 要集中在9:00-10:00之间, 49-54年生小叶杨则较晚, 主要集中在13:00-14:30之间(左力翔等, 2014)。本研 究所选取的刺槐为近熟林, 侧柏为幼龄林, 缺少同 一树种不同林龄间的比较, 有必要开展进一步的研 究, 以阐明林龄对树干液流的影响。整个生长季阔 叶树种刺槐的 $F_{\mathrm{d}}$ 明显高于针叶树种侧柏, 液流峰值 最大值分别为 $0.12068 \mathrm{~m}^{3} \cdot \mathrm{m}^{-2} \cdot \mathrm{h}^{-1} 、 0.03737 \mathrm{~m}^{3} \cdot \mathrm{m}^{-2}$. $\mathrm{h}^{-1}$, 这与孙慧珍等(2005)对不同木材结构树干液流 对比研究的相关结论一致。

影响树木蒸腾耗水过程的诸多环境因素大多具 有协同效应(张建国等, 2011)。例如, $R_{\mathrm{s}}$ 会影响气孔的 开闭和环境温度, $V P D$ 又是温度和湿度的综合体现。 在气孔处于同一状态下的蒸腾作用, 通常只与 $V P D$

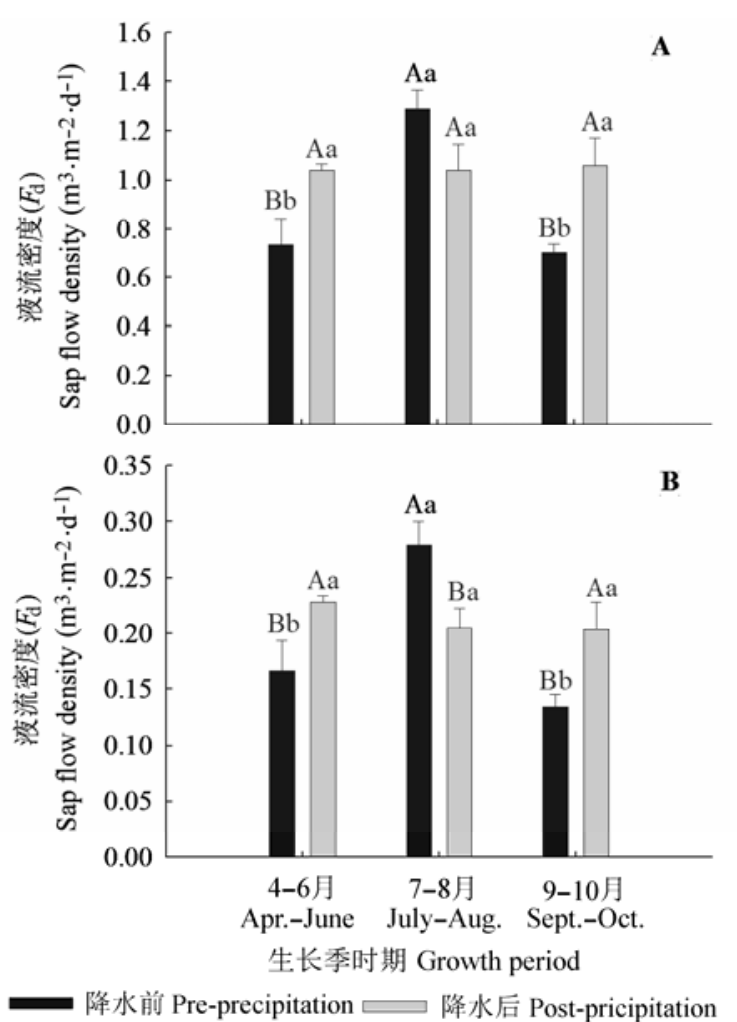

图6 生长季内不同生长时期降水前后刺槐(A)和侧柏 $(\mathbf{B})$ 的 液流密度 $\left(F_{\mathrm{d}}\right)$ (平均值土标准误差)。不同大写字母表示同一时 期降水前后差异显著, 不同小写字母表示不同月份降水前 或降水后的差异显著 $(p<0.05)$ 。

Fig. 6 Sap flow density $\left(F_{\mathrm{d}}\right)$ of Robinia pseudoacacia $(\mathbf{A})$ and Platycladus orientalis (B) measured on pre- and post-precipitation conditions, respectively, during the different growth periods. Capital letters indicated the significant difference between the pre- and post-precipitation at 0.05 levels, and small letters indicated the significant difference among months in pre- or post-precipitation at 0.05 levels.

呈简单的相关关系，但如果某个环境因素(温度、湿 度、土壤水分或光照)限制了气孔的开闭状态，那么 蒸腾作用就会发生相应变化, 这些环境因素同 $F_{\mathrm{d}}$ 的 关系也可能表现为非线性关系(Du et al., 2011)。本 研究区位于黄土丘陵地区, 生长季内不同生长时期 降水前后 $R_{\mathrm{s}}$ 与 $V P D$ 存在显著的相关关系, 变化趋势 基本相同。因此, 采用指数饱和曲线可以反映 $F_{\mathrm{d}}$ 对 $R_{\mathrm{S}}$ 和 $V P D$ (即 $V T$ ) 的响应特征, 并根据方程中的拟合 系数可以看出不同时期的特点。

回归曲线显示: 随着 $V T$ 的升高, 刺槐和侧柏的 $F_{\mathrm{d}}$ 都逐渐达到饱和水平 $\left(V T\right.$ 约为 $\left.50 \mathrm{kPa}\left(\mathrm{W} \cdot \mathrm{m}^{-2}\right)^{1 / 2}\right)$, 表明刺槐和侧柏都启动了气孔调节机能。同时, 生 长季内不同生长时期降水前后的拟合参数 $(a, b)$ 也 存在明显差异(表2)。降水前刺槐和侧柏 $F_{\mathrm{d}}$ 随着 $V T$ 的 升高上升缓慢, 尤其是典型干旱时期(4-6月), 曲线 

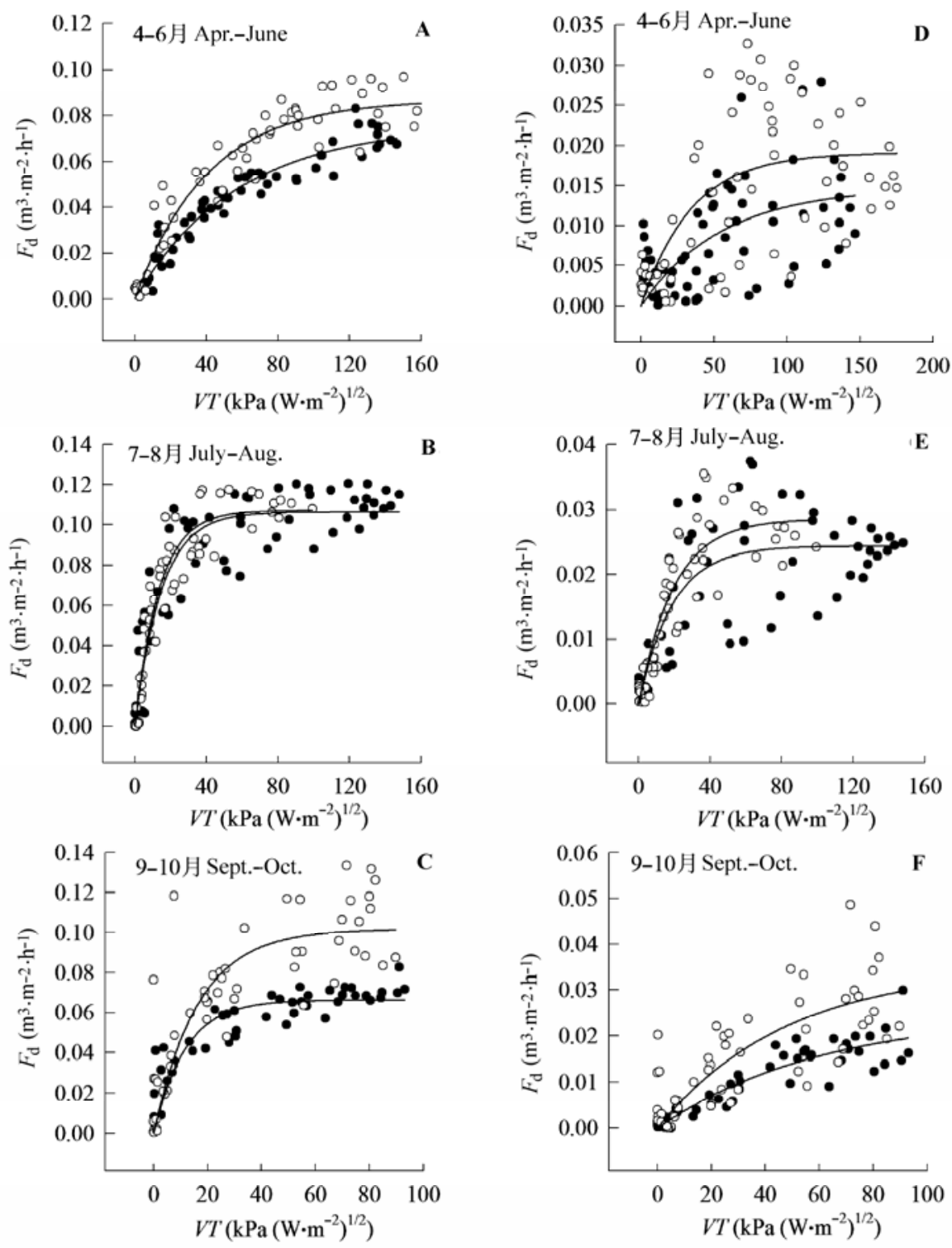

图7 生长季内不同生长时期降水前 $(\bullet)$ 后 $(O)$ 刺槐 $(\mathbf{A}-\mathbf{C})$ 和侧柏 $(\mathbf{D}-\mathbf{F})$ 液流密度 $\left(F_{\mathrm{d}}\right)$ 和蒸滕变量 $(V T)$ 的关系。

Fig. 7 The relationship between sap flow density $\left(F_{\mathrm{d}}\right)$ and transpiration $(V T)$ of Robinia pseudoacacia $(\mathbf{A}-\mathbf{C})$ and Platycladus orientalis (D-F) measured on pre $(\bullet)$ and post-precipitation $(O)$ condition, respectively, during the different growth periods.

拟合参数 $b$ 值较小 $(0.01$ 左右 $)$, 说明树木导水能力较 低，蒸腾受到抑制，气孔处于不完全开放状态，该 时期树干液流已受到土壤水分的影响; 而降水后相 对降水前均有所改善, 这可能是由于降水使土壤水 分得到暂时补充(图2), 木质部导水率提高引起的 (Eberbach \& Burrows, 2006)。整个生长季内刺槐水 力导度基本呈增加趋势, 且降水前后刺槐比侧柏变 化显著 $(p<0.001)$, 刺槐导水能力整体大于侧柏, 表 明刺槐可能是通过降低其叶片水势增强水分吸收, 以维持一定的光合和蒸腾作用水平 (杨建伟等, 2006)。拟合曲线降水后较降水前不同程度向上偏
移, 且刺槐偏移量(拟合参数 $a$ )大于侧柏, 说明刺槐 对降水前后环境因素变化更为敏感。Du等(2011)对 黄土高原半干旱区3种不同林分类型液流特征对比 的研究也表明, 引入种刺槐为干旱敏感型树种, 随 着降水事件的发生有较高液流响应, 林地土壤水分 变化对其蒸腾耗水影响较大; 而乡土树种辽东栎 (Quercus liaotungensis)、山杏(Armeniaca sibirica)等 干旱不敏感型树种随降水事件的发生, 其液流响应 不明显，表明相对干旱敏感型树种其水分利用更为 保守。关于树木对季节性干旱或降水响应的敏感性 与林龄的关系, Delzon和Loustau (2005)的研究表 
表2 生长季内不同生长时期降水前后液流密度 $\left(F_{\mathrm{d}}\right)$ 和蒸滕变量 $(V T)$ 的拟合结果

Table 2 Sap flow density $\left(F_{\mathrm{d}}\right)$ in relation to transpiration $(V T)$ of pre- and post-precipitation days in different growth periods during the growing season

\begin{tabular}{|c|c|c|c|c|}
\hline $\begin{array}{l}\text { 树种 } \\
\text { Species }\end{array}$ & $\begin{array}{l}\text { 月份 } \\
\text { Month }\end{array}$ & $\begin{array}{l}\text { 降水前 } \\
\text { Pre-precipitation }\end{array}$ & $\begin{array}{l}\text { 降水后 } \\
\text { Post-precipitation }\end{array}$ & $\begin{array}{c}\text { 拟合参数检验 } \\
\text { Difference between coefficients }\end{array}$ \\
\hline \multirow[t]{11}{*}{ 刺槐 Robinia pseudoacacia } & 4-6月 & $a=0.07597$ & $a=0.08689$ & $p<0.001$ \\
\hline & \multirow[t]{2}{*}{ Apr.-June } & $b=0.01751$ & $b=0.02463$ & $p<0.001$ \\
\hline & & $\begin{array}{l}R^{2}=0.93595 \\
n<0.001\end{array}$ & $\begin{array}{l}R^{2}=0.90636 \\
n<0.001\end{array}$ & \\
\hline & 7-8月 & $a=0.10655$ & $a=0.10735$ & $p=0.064$ \\
\hline & \multirow[t]{3}{*}{ July-Aug. } & $b=0.06804$ & $b=0.07429$ & $p=0.064$ \\
\hline & & $R^{2}=0.85815$ & $R^{2}=0.92151$ & \\
\hline & & $p<0.001$ & $p<0.001$ & \\
\hline & 9-10月 & $\mathrm{a}=0.0665$ & $a=0.10192$ & $p<0.001$ \\
\hline & \multirow[t]{3}{*}{ Sept.-Oct. } & $b=0.08483$ & $b=0.06069$ & $p<0.001$ \\
\hline & & $R^{2}=0.8779$ & $R^{2}=0.67764$ & \\
\hline & & $p<0.001$ & $p<0.001$ & \\
\hline \multirow{12}{*}{ 侧柏 Platycladus orientalis } & 4-6月 & $a=0.01478$ & $a=0.01916$ & $p<0.01$ \\
\hline & \multirow[t]{3}{*}{ Apr.-June } & $b=0.01808$ & $b=0.02917$ & $p<0.01$ \\
\hline & & $R^{2}=0.27474$ & $R^{2}=0.39464$ & \\
\hline & & $p<0.001$ & $p<0.001$ & \\
\hline & 7-8月 & $a=0.02437$ & $a=0.02851$ & $p<0.05$ \\
\hline & \multirow[t]{3}{*}{ July-Aug. } & $b=0.05265$ & $b=0.05112$ & $p<0.05$ \\
\hline & & $R^{2}=0.64406$ & $R^{2}=0.83689$ & \\
\hline & & $p<0.001$ & $p<0.001$ & \\
\hline & 9-10月 & $a=0.02438$ & $a=0.03512$ & $p<0.001$ \\
\hline & \multirow[t]{3}{*}{ Sept.-Oct. } & $b=0.01681$ & $b=0.02075$ & $p<0.001$ \\
\hline & & $R^{2}=0.81975$ & $R^{2}=0.57574$ & \\
\hline & & $p<0.001$ & $p<0.001$ & \\
\hline
\end{tabular}

明: 54年生海岸松(Pinus pinaster)和10年生的相比, $F_{\mathrm{d}}$ 下降的同时其干旱敏感性也显著减低; Dunn和 Connor (1993)的研究则表明: 50年生和90年生的澳大 利亚桉树(Eucalyptus regnans) 的 $F_{\mathrm{d}}$ 及其对干旱的敏 感性并没有显著差异。因此, 树木对干旱或降水事件 响应的敏感性与林龄的关系还需要进一步分析。

根系分布特点在一定程度上也反映了植物对由 降水引起的土壤水分条件变化响应的敏感性(Kume et al., 2007)。对刺槐和侧柏林地根系垂直分布的调 查发现: 0-60 cm为主要的根系分布层, 在这一深度 范围内, 刺槐的有效根系(直径 $\leqslant 1 \mathrm{~mm}$ )主要分布在 20-30 cm 土层, 侧柏的有效根系主要分布在10-20 $\mathrm{cm}$ 土层。刺槐和侧柏林地的平均有效根重密度分别 为 $0.14 \mathrm{mg} \cdot \mathrm{cm}^{-3} 、 0.29 \mathrm{mg} \cdot \mathrm{cm}^{-3}$, 刺槐的有效根重密 度明显小于侧柏, 若遇到长期干旱, 少量降水对刺 槐林地土壤水分贡献并不大, 即不能有效缓解土壤 水分亏缺, 这也是整个生长季内同一生长时期(除 7-8月刺槐)降水前后液流均有显著性差异的原因。 在经历了春末和夏初的干旱后, 土壤水分已严重不 足(图2), 虽然7-8月已经进入该地区的雨季, 但由 于该时期所选降水事件的降水量较少 (7 mm), 加之 此时正值刺槐生长旺盛季, 其蒸腾耗水对土壤水分 需求相对较大, 所以该生长时期降水前后液流水平 差异性不显著(图6)。然而, 如果要进一步了解和掌 握不同树种根系和植物水分利用策略的关系, 则需 要更为详细的根系调查辅助。
在黄土丘陵区, 由于经常发生的季节性干旱的 影响, 每个树种都必须通过调整其水分利用策略以 适应环境胁迫(Ares et al., 2008)。因此, 对比分析黄 土丘陵区刺槐和侧柏人工林树干液流特征及其对降 水响应的差异, 了解各自水分利用特点, 对于评估 该区不同林分类型水分利用差异模型的建立及可持 续性造林树种的选择都有一定的理论价值。本试验 着重分析了生长季内不同生长时期树干液流特征对 降水等影响因素的响应特点, 因此只选取了生长季 3 个不同生长时期有代表性的降水事件前后时段进 行分析。而后续的分析还需基于更长时间尺度上的 观测, 才能深入理解不同林龄不同树种对当地水分 环境条件变化的响应规律。

\section{4 结论}

1)刺槐和侧柏在不同月份降水前后树干液流都 呈单峰型的日变化特征。每天7:00前后开始启动, 10:00-13:00达到最大值, 19:00前后开始下降, 直至 次日树干液流启动之前降至最低值, 刺槐 $F_{\mathrm{d}}$ 整体较 侧柏的高。

2)生长季内不同生长时期 $F_{\mathrm{d}}$ 和 $V T$ 的回归曲线分 析表明, 随着 $V T$ 的升高, 刺槐和侧柏树干液流都逐 渐趋于稳定 $\left(V T\right.$ 约为 $\left.50 \mathrm{kPa}\left(\mathrm{W} \cdot \mathrm{m}^{-2}\right)^{1 / 2}\right)$ 。

3)根据降水前后树干液流特征以及植物导水系 统的水分供应分析, 将刺槐和侧柏划分为 2 种响应 类型: 刺槐为降水敏感型树种, 表现为随降水事件 
的发生有较高液流值的响应，蒸腾耗水对土壤水分 需求大; 而侧柏为降水不敏感型树种, 降水前后液 流响应相对不敏感，水分利用相对保守。

基金项目 国家自然科学基金(41371506)、公益性 行业(国家气象局)科研专项(重大专项)(GYHY2015060013)和西北农林科技大学博士科研启动费 (Z109021508)。

\section{参考文献}

Ares A, Harrington CA, Terry TA, Kraft JM (2008). Vegetation control effects on untreated wood, crude cellulose and holocellulose $\delta^{13} \mathrm{C}$ of early and latewood in 3- to 5-yearold rings of Douglas-fir. Trees, 22, 603-609.

Burgess SSO (2006). Measuring transpiration responses to summer precipitation in a Mediterranean climate: A simple screening tool for identifying plant water-use strategies. Physiologia Plantarum, 127, 404-412.

Campbell GS, Norman JM (1998). An Introduction to Environmental Biophysics. Springer-Verlag, New York.

Chen YM, Liu GB, Xu BC (2005). Effects of artificial Seabuckthorn forest on soil and water conservation in Loess hilly region. Chinese Journal of Applied Ecology, 16, 595-599. [陈云明, 刘国涁, 徐炳成 (2005). 黄土丘陵 区人工沙棘林水土保持作用机理及效益. 应用生态学 报, 16, 595-599.]

Chow GC (1960). Tests of equality between sets of coefficients in two linear regressions. Econometrica, 28, 591-605.

Delzon S, Loustau D (2005). Age-related decline in stand water use: Sap flow and transpiration in a pine forest chronosequence. Agricultural and Forest Meteorology, 129, 105-119.

Du S, Wang YL, Kume T, Zhang JG, Otsuki K, Yamanaka N, Liu GB (2011). Sapflow characteristics and climatic responses in three forest species in the semiarid Loess Plateau region of China. Agricultural and Forest Meteorology, 151, 1-10.

Dunn GM, Connor DJ (1993). An analysis of sap flow in mountain ash (Eucalyptus regnans) forests of different age. Tree Physiology, 13, 321-336.

Eberbach PL, Burrows GE (2006). The transpiration response by four topographically distributed Eucalyptus species, to rainfall occurring during drought in south eastern Australia. Physiologia Plantarum, 127, 483-493.

Ewers BE, Mackay DS, Samanta S (2007). Interannual consistency in canopy stomatal conductance control of leaf water potential across seven tree species. Tree Physiology, 27, $11-24$.

Fan M, Ma LY, Wang RH (2008). Variation of stem sap flow of Robinia pseudoacacia in spring and summer. Scientia Silvae Sinicae, 44(1), 41-45. (in Chinese with English abstract) [樊敏, 马履一, 王瑞辉 (2008). 刺槐春夏季树干 液流变化规律. 林业科学, 44(1), 41-45.]
Gao SM, Yang FK, Su YS (2003). Investigation into the Ecological Agriculture Construction in Hilly-gully Region of the Loess Plateau. Yellow River Water Conservancy Press, Zhengzhou. (in Chinese) [高世铭, 杨封科, 苏永生 (2003). 陇中黄土丘陵沟壑区生态环境建设与农业可持 续发展研究. 黄河水利出版社, 郑州.]

Granier A (1987). Evaluation of transpiration in a Douglas-fir stand by means of sap flow measurements. Tree Physiology, 3, 309-320.

He YT, Li WH, Li GC, Min QW, Zhao HZ (2004). Ecological water requirement of forests in Loess Plateau. Chinese Journal of Environmental Science, 25(3), 35-39. [何永涛, 李文华, 李贵才, 闵庆文, 赵海珍 (2004). 黄土高原地 区森林植被生态需水研究. 环境科学, 25(3), 35-39.]

Hölscher D, Koch O, Korn S, Leuschner C (2005). Sap flux of five co-occurring tree species in a temperate broad-leaved forest during seasonal soil drought. Trees, 19, 628-637.

Hou QC, Han RL (2000). Problems on vegetation construction in Loess Plateau region. Bulletin of Soil and Water Conservation, 20(2), 53-56. (in Chinese with English abstract) [侯庆春, 韩芯莲 (2000). 黄土高原植被建设中的有关 问题. 水土保持通报, 20(2), 53-56.]

Hou QC, Han RL, Han SF (1999).The problem of "soil dry layer” of plantation grass in Loess Plateau. Soil and Water Conservation in China, (5), 11-14. (in Chinese with English abstract) [侯庆春, 韩芯莲, 韩仕锋 (1999). 黄土高 原人工林草地“土壤干层”问题初探. 中国水土保持, (5), 11-14.]

Iida S, Nakatani S, Tanaka T (2006). Evaluation of transpiration from a natural deciduous broad-leaved forest located at a headwater catchment based on measurement of sap flux density. Journal of Japan Society of Hydrology and Water Resources, 19, 7-16.

Kume T, Takizawa H, Yoshifuji N, Tanaka K, Tantasirin C, Tanaka N, Suzuki M (2007). Impact of soil drought on sap flow and water status of evergreen trees in a tropical monsoon forest in northern Thailand. Forest Ecology and Management, 238, 220-230.

Liu YH, Shi JA, Han QF, Jia ZK, Ren HY, Wu XW (2007). Calibration study of the determination of alfalfa soil moisture with neutron probe. Agricultural Research in the Arid Areas, 25(2), 115-119. (in Chinese with English abstract) [刘玉华, 史纪安, 韩清芳, 贾志宽, 任鸿远, 吴新卫 (2007). 中子仪测定苗宿田土壤含水量的标定研究. 干 旱地区农业研究, 25(2), 115-119.]

Ma LY, Wang HT (2002). Spatial and chronic fluctuation of sapwood flow and its relevant variables of Pinus tabulaeformis. Journal of Beijing Forestry University, 24(3), 2327. (in Chinese with English abstract) [马履一, 王华田 (2002). 油松边材液流时空变化及其影响因子研究. 北 京林业大学学报, 24(3), 23-27.]

Oren R, Zimmermann R, Terbough J (1996). Transpiration in 
upper Amazonia floodplain and upland forests in response to drought-breaking rains. Ecology, 77, 968-973.

Pataki DE, OrenR, Smith WK (2000). Sap flux of co-occurring species in a western subalpine forest during seasonal soil drought. Ecology, 81, 2257-2566.

Shan L (1988). Realist approches and future strategy for increasing productivity in dry farmland, semiarid areas. Memoir of Northwestern Institute of Soil and Water Conservation Academia Sinica, (2), 1-9. (in Chinese) [山 仑 (1988). 提高半干旱地区旱地农田生产力的现实途 径和未来策略. 中国科学院西北水土保持研究所集刊, (2), 1-9.]

Sun HZ, Li YP, Wang C, Zhou XF (2005). Comparative study on stem sap flow of non- and ring-porous tree species. Chinese Journal of Ecology, 24, 1434-1439. (in Chinese with English abstract) [孙慧珍, 李夷平, 王翠, 周晓峰 (2005). 不同木材结构树干液流对比研究. 生态学杂志, 24, 1434-1439.]

Wang Y, Wang J (2012). Research advance in sap flow of plants. Anhui Agricultural Science Bulletin,18(5), 49-50. (in Chinese) [汪滢, 王健 (2012). 植物液流研究进展. 安徽农学通报, 18(5), 49-50.]

Wei TX, Zhu JZ, Zhang XP (1991). Methods of measuring stand vapor transpiration. Journal of Beijing Forestry University, 21(3), 85-91. (in Chinese with English abstract) [魏天兴, 朱金兆, 张学培 (1991). 林分蒸散耗水 量测定方法述评. 北京林业大学学报, 21(3), 85-91.]

Wei YF, Fang J, Liu S, Zhao XY, Li SG (2013). Stable isotopic observation of water use sources of Pinus sylvestris var. mongolica in Horqin Sandy Land, China. Trees, 27, 12491260.

Wu F, Chen YM, Yu ZH (2010). Growing season sap-flow dynamics of Robinia pseudoacacia plantation in the semi-arid region of Loess Plateau, China. Chinese Journal of Plant Ecology, 34, 469-476. (in Chinese with English abstract) [吴芳, 陈云明, 于占辉 (2010). 黄土高原半干 旱区刺槐生长盛期树干液流动态. 植物生态学报, 34, 469-476.]

Wu QX, Yang WZ (1998). Forest and Grassland Vegetation Construction and Its Sustainable Development in Loess Plateau. Science Press, Beijing. (in Chinese) [吴钦孝, 杨 文治 (1998). 黄土高原植被建设与持续发展. 科学出版 社, 北京.]

Xu GQ, Li Y (2009). Roots distribution of three desert shrubs and their response to precipitation under co-occurring conditions. Acta Ecologica Sinica, 29, 130-137. (in Chinese with English abstract) [徐贵青, 李彦 (2009). 共生 条件下三种荒漠灌木的根系分布特征及其对降水的响 应. 生态学报, 29, 130-137.]

Xu PH, Chen YM, Wu F (2009). Effects different improvement measures of degradated Robinia pseudoacacia in semi-arid Loess Hilly region. Journal of Northwest Forestry
University, 24(4), 109-113. (in Chinese with English abstract) [许鹏辉, 陈云明, 吴芳 (2009). 黄土丘陵半干 旱区退化刺槐林不同改造方式效果分析. 西北林学院 学报, 24(4), 109-113.]

Xu WT, Zhao P, Wang Q, Rao XQ, Cai XA, Zeng XP (2007). Calculation and modeling of the canopy stomatal conductance of Acacia mangium from sap flow data. Acta Ecologica Sinica, 27, 4122-4131. (in Chinese with English abstract) [许文滔, 赵平, 王权, 饶兴权, 蔡锡安, 曾 小平 (2007). 基于树干液流测定值的马占相思(Acacia mangium) 冠层气孔导度计算及数值模拟. 生态学报, 27 , 4122-4131.]

Yang JW, Liang ZS, Han RL (2006). Water use efficiency characteristics of four tree species under different soil water conditions in the Loess Plateau. Acta Ecologica Sinica, 26, 558-565. (in Chinese with English abstract) [杨建伟, 梁宗锁, 韩芯莲 (2006). 黄土高原常用造林树种水分利 用特征. 生态学报, 26, 558-565.]

Yu ZH, Chen YM, Du S (2009a). Sap flow dynamics in the leaf-flushing period of a Robinia pseudoacacia plantation in semi-arid region of Loess Plateau. Scientia Silvae Sinicae, 45(4), 53-59. (in Chinese with English abstract) [于占辉, 陈云明, 杜盛 (2009a). 黄土高原半干旱区人工林刺槐展 叶期树干液流动态分析. 林业科学, 45(4), 53-59.]

Yu ZH, Chen YM, Du S (2009b). The sapflow dynamics of Platycladus orientali in the semi-arid Loess Plateau region. Acta Ecologica Sinica, 29, 3970-3976. (in Chinese with English abstract) [于占辉, 陈云明, 杜盛 (2009b). 黄土高原半干旱区侧柏(Platycladus orientalis)树干液流 动态. 生态学报, 29, 3970-3976.]

Zhang JG, Kume T, Otsuki K, Yamanaka N, Du S (2011). Sap flow dynamics of dominant trees of Quercus liaotungensis forest in the semiarid Loess Plateau region. Scientia Silvae Sinicae, 47(4), 63-69. (in Chinese with English abstract) [张建国, 久米朋宣, 大规恭一, 山中典和, 杜盛 (2011). 黄土高原半干旱区辽东柇的树干液流动态. 林 业科学, 47(4), 63-69.]

Zhang JT (2004). Theory and techniques of vegetation restoration and construction on Loess Plateau, China. Journal of Soil and Water Conservation, 18(5), 120-124. (in Chinese with English abstract) [张金屯 (2004). 黄土高原植被恢 复与建设的理论和技术问题. 水土保持学报, 18(5), 120-124.]

Zuo LX, Chen JC, Li YY (2014). Water use strategies of different ages of Populus simonii on sandy land of northern Shaanxi. Science of Soil and Water Conservation, 12(6), 59-67. (in Chinese with English abstract) [左力翔, 陈佳村, 李种种 (2014). 陕北沙地不同树龄小叶杨的水 分利用策略. 中国水土保持科学, 12(6), 59-67.]

责任编委: 高玉葆 责任编辑: 李 敏 